\title{
O PPA como instrumento de planejamento e gestão estratégica
}

Luiz Fernando Arantes Paulo

\section{Introdução}

O Plano Plurianual (PPA), criado pela Constituição Federal de 1988 (CF/ 88), ainda padece de uma crise de identidade. Não obstante o papel previsto de orientador das peças orçamentárias, o certo é que, durante esses 22 anos, o PPA ainda não foi reconhecido como um efetivo instrumento de planejamento e gestão estratégica ${ }^{1}$.

De fato, há quem afirme que ele não foi concebido para desempenhar esse papel, e na administração federal ainda há uma considerável resistência a sua efetiva incorporação. Como reflexo, sua tramitação no Congresso Nacional também não mobiliza os parlamentares, que se limitam à discussão de itens reproduzidos no orçamento anual. Nesse contexto, o PPA é comumente definido como um documento burocrático e de pouca utilidade.

No presente trabalho, procuramos demonstrar que, apesar do legislador constituinte ter criado o PPA para ser um instrumento de planejamento e gestão 
estratégica, com o papel de integrar o planejamento à execução das políticas públicas, a estrutura e as opções metodológicas adotadas ao longo dos anos o têm afastado desse propósito.

Para tanto, partiremos de interpretação lógica e sistemática da Carta Magna para procurar definir o papel a ser desempenhado pelo PPA. De fato, a imprecisão conceitual nos parece um obstáculo para a implementação do instrumento, em especial quando o mesmo deve ser construído a partir de um trabalho de negociação entre os diversos órgãos da administração pública, por meio de abordagens matriciais e horizontais, em um trabalho de coordenação e não de imposição hierárquica.

Em seguida, após uma breve abordagem histórica, apresentaremos de forma resumida a metodologia de construção do PPA, em especial a adotada a partir de 2000, que introduziu o programa como unidade de gestão. Em linhas gerais, essa é a metodologia adotada até hoje e busca proporcionar a integração entre planejamento, orçamento e gestão.

Após, serão apresentadas abordagens críticas sobre a evolução do PPA a partir de 2000 à luz das definições conceituais anteriormente expostas e da estratégia de integração entre planejamento, orçamento e gestão, de forma a evidenciar quais os principais fatores que contribuem para o não reconhecimento do PPA como instrumento de planejamento e gestão estratégica.

Diante dos problemas apontados, serão sugeridas algumas modificações à estrutura e à gestão do PPA, que podem contribuir para o reconhecimento deste como um instrumento de planejamento e gestão estratégica.

A conclusão reúne, de maneira sintética, as principais ideias desenvolvidas em todo o texto, como forma de reforçar os argumentos apresentados.

Cabe esclarecer que o presente estudo concentra-se em aspectos técnicos e metodológicos, embora reconheça que o planejamento governamental é um exercício essencialmente político. A ideia central é: quanto melhor a base técnica e metodológica do plano, melhor o debate acerca das políticas públicas a serem implementadas por meio dele.

\section{A finalidade do Plano Plurianual}

O Plano Plurianual é uma lei, de iniciativa do Poder Executivo, que deve estabelecer, "de forma regionalizada, as diretrizes, objetivos e metas da administração pública federal para as despesas de capital e outras delas decorrentes e para as relativas aos programas de duração continuada" (CF/88, art. $\left.165, \int 1^{\circ}\right)$.

Está previsto no Título VI (Da Tributação e do Orçamento), Capítulo II (Das Finanças Públicas), Seção II (Dos Orçamentos), junto com a Lei de Diretrizes Orçamentárias (LDO) e a Lei Orçamentária Anual (LOA).

É possível afirmar que a Constituição Federal atribuiu ao PPA um papel central de organização da ação do Estado, uma vez que submete a elaboração dos demais documentos de planejamento e orçamento às suas disposições. De forma textual, a Carta Magna estabelece que os planos e programas nacionais, regionais e setoriais devem ser elaborados em consonância

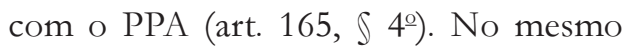
sentido, a LDO e a LOA não devem conter dispositivos incompatíveis com o Plano Plurianual (art. 166).

A intenção do legislador constituinte foi a de reconhecer o planejamento como 
uma função indispensável ao Estado, e não uma opção do governante. Tanto é assim que, apesar de prever a edição de Lei Complementar (LC) para dispor sobre exercício financeiro, vigência, prazos, elaboração e organização, fez constar no Ato das Disposições Constitucionais Transitórias (ADCT) duas importantes disposições:

- A vigência do PPA inicia no segundo ano do mandato presidencial e termina no final do primeiro exercício do mandato presidencial subsequente (ADCT, art. 35).

- Os Poderes Executivo, Legislativo e Judiciário manterão sistema de controle interno com a finalidade de avaliar o cumprimento das metas previstas no PPA (ADCT, art. 74).

Apesar da clareza das disposições constitucionais, o reconhecimento do caráter estratégico do PPA ainda encontra resistência, seja no âmbito da administração, seja entre estudiosos, parlamentares e especialistas. Nesse sentido, Ronaldo Coutinho Garcia, especialista do Instituto de Pesquisas Econômicas Aplicadas (IPEA), afirma que a Constituição seguiu uma concepção normativa e reducionista de planejamento, herdada do período militar, ao incluir o PPA em seção destinada aos orçamentos (GARCIA, 2000).

Não nos parece, contudo, que a Constituição mereça tais críticas. O seu posicionamento na seção "Dos Orçamentos" é plenamente justificável pelo seu caráter orientador vinculativo. De fato, o legislador constituinte foi sábio em reconhecer que a materialização do Plano só é possível se o mesmo for contemplado nas leis orçamentárias.

$A$ introdução de um plano de médio prazo como parte de uma política orçamentária denota a intenção clara do legislador constituinte em proporcionar maior racionalidade à ação estatal de forma a impulsionar o desenvolvimento, o qual se daria por dois movimentos simultâneos:

- o estabelecimento dos gastos governamentais a partir de uma visão de futuro e de estratégias definidas, submetidas à aprovação do Congresso Nacional, com força normativa;

- a viabilidade fiscal para implementação das políticas.

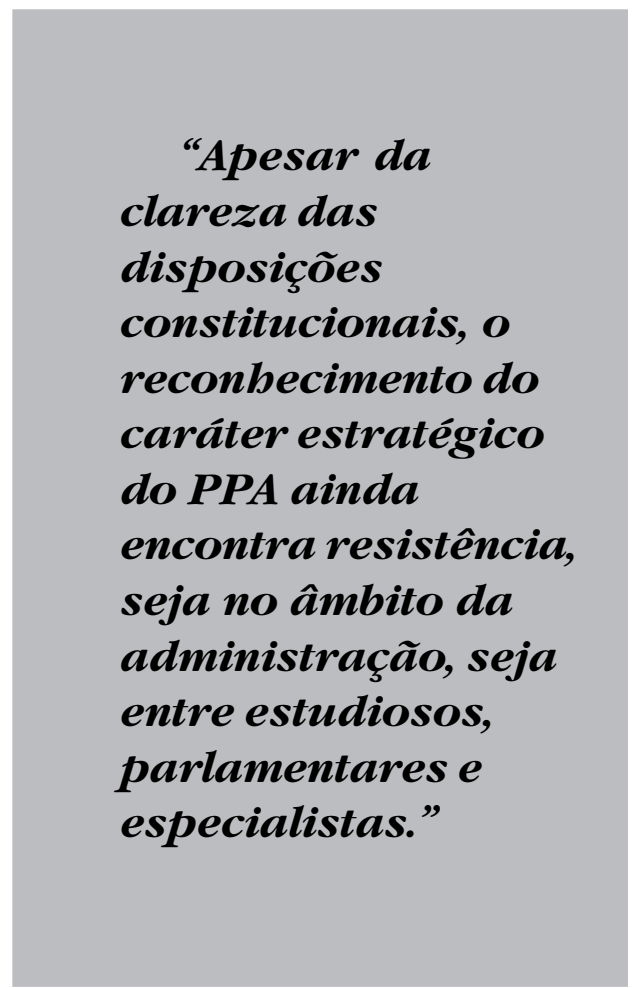

O Plano Plurianual, portanto, deve estabelecer a ligação entre objetivos indicativos de Estado, presentes em um planejamento de longo prazo; políticas de governo, de médio prazo, e, finalmente, realização dos gastos, previstos pelo orçamento anual.

A figura a seguir traz uma representação gráfica desse papel conciliador do PPA entre as políticas de Estado e de governo2: 
Assim, não há por que valorizar essa suposta celeuma, uma vez que um orçamento não deixa de ser um plano, e um plano elaborado sob premissas de viabilidade fiscal não deixa de ser um orçamento. O certo é que a Constituição previu que a realização da despesa pública será precedida pela apreciação de três leis orçamentárias, das quais o PPA é a mais estratégica.

Ao submeter as diretrizes, objetivos e metas da administração pública federal para apreciação e aprovação pelo Congresso Nacional, o Plano Plurianual tem a finalidade de construir um compromisso político entre os Poderes Executivo e Legislativo, orientando a formulação das leis orçamentárias e dos planos setoriais, bem como a execução das políticas públicas.

Portanto, é possível afirmar que o PPA foi concebido para ser um instrumento de planejamento estratégico, na medida em que estabelece um compromisso político para além do mandato presidencial, que vai orientar a formulação das leis orçamentárias e planos setoriais e regionais. É também um instrumento de gestão estratégica, uma vez que o cumprimento das metas estabelecidas deve ser avaliado pelos Poderes Executivo, Legislativo e Judiciário.

\section{Breve histórico}

Apenas para que não se perca a perspectiva histórica, é oportuno destacar que o Brasil é considerado um país com tradição em planejamento, sendo que os primeiros esforços nesse sentido podem ser identificados no início da década de 30 do século XX, com o Niemeyer Report, de $1931^{3}$, que apresentava estudo com alternativas à superação da crise econômica vivida no Brasil após a depressão de 1929.

A partir dos anos 1940, o Brasil lançou numerosos planos de desenvolvimento. Como exemplos históricos, podem ser citados: Plano SALTE Saúde, Alimentação, Transporte e Energia (1947), Plano de Metas (1956) e os Planos Nacionais de Desenvolvimento (I e II PNDs, de 1972 a 1974 e de 1975 a 1979, respectivamente).

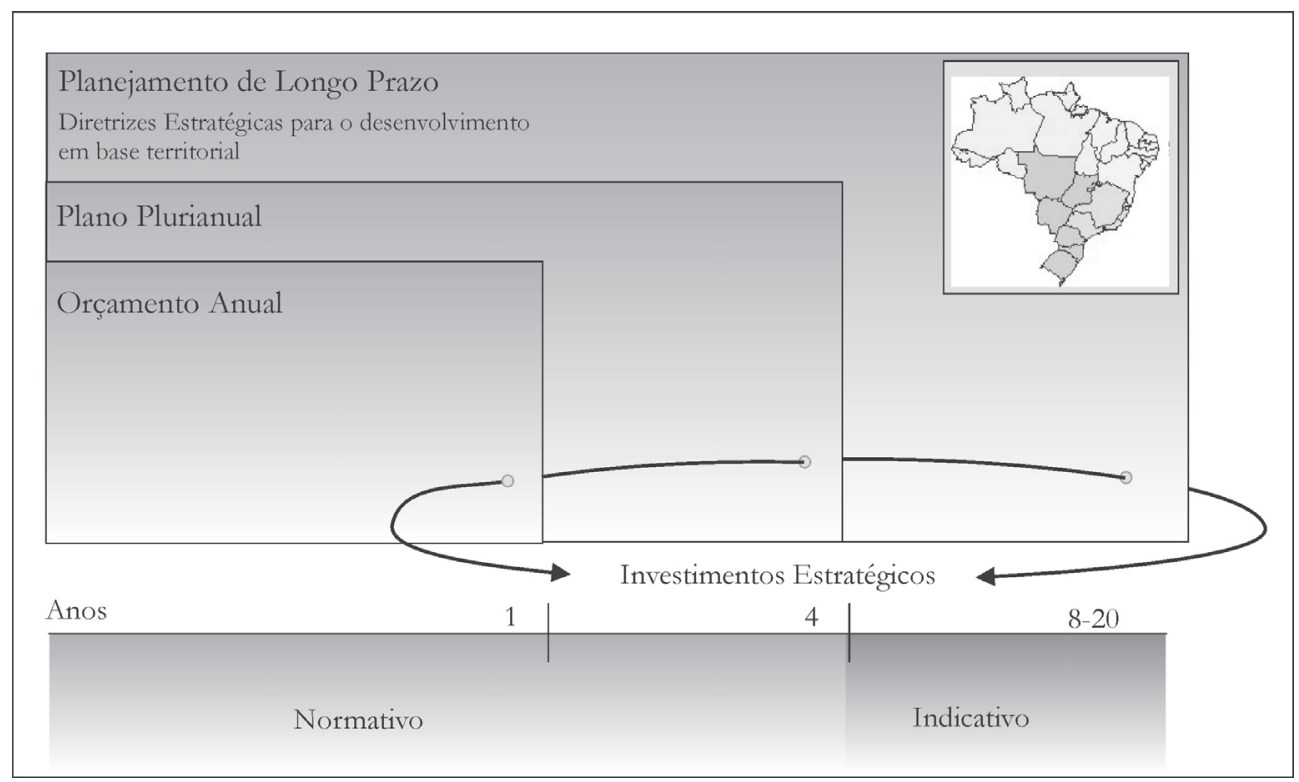


Com a crise de 1979 e a diminuição da disponibilidade de recursos externos, o déficit nas contas públicas provocou no país um ciclo de descontrole inflacionário que contribuiu para o enfraquecimento do planejamento.

Com a redemocratização, o planejamento governamental voltou a figurar como uma atribuição inafastável do Estado, sendo previsto na Constituição Federal de 1988 por meio da obrigação de elaboração de planos plurianuais.

O primeiro Plano Plurianual (1991$1995)^{4}$ tinha como principais objetivos o controle das contas públicas e um projeto de desestatização e abertura comercial. Esse primeiro PPA não foi reconhecido como instrumento derivado de um exercício de planejamento. Foi encaminhado ao Congresso Nacional de forma burocrática e aprovado sem maiores debates, de forma a cumprir a formalidade da previsão constitucional (GARCIA, 2000)5.

O PPA 1996-1999 buscava garantir a estabilidade econômica conquistada com o Plano Real e remover obstáculos para a retomada do crescimento. Além da valorização do planejamento governamental, como inovação, o mencionado PPA não só trazia a perspectiva de investimentos públicos da União, como previa o estabelecimento de parcerias, tanto com os entes públicos (estados e municípios) quanto com a iniciativa privada. Foi apresentado um mapeamento das demandas e oportunidades ${ }^{6}$, a fim de orientar os diversos agentes econômicos e estabelecer uma sinergia de esforços para o cumprimento de metas.

O PPA 1996-1999 também promoveu um novo arranjo de gestão, com a instituição da figura do gerente para 42 projetos estratégicos, que acabou por orientar algumas das mudanças promovidas no PPA seguinte.
O PPA 2000-20037 foi um marco na organização da ação estatal, ao estabelecer o programa como unidade de gestão e disciplinar a integração entre planejamento, orçamento e gestão. A metodologia de construção desse plano é, em linhas gerais, a utilizada até hoje. A partir de 2000, toda iniciativa governamental foi organizada em programas com foco em resultados e, inspirado no bom desempenho dos projetos estratégicos do "Brasil em Ação", foi atribuído um gerente a cada programa de governo.

O PPA 2004-2007 adotou a estratégia de consolidação da metodologia lançada no plano anterior, tendo o programa como unidade de gestão voltada para resultados. A inovação proposta foi a inserção da participação social na elaboração e gestão do plano, que se materializou durante o processo de confecção, em eventos realizados em todos os estados e Distrito Federal. Contudo, durante a gestão do plano não foram estabelecidos mecanismos sistêmicos para promover a desejada participação?.

O PPA 2008-2011 ${ }^{10}$ mantém a estrutura por programas, promovendo mudanças pontuais em aspectos ligados à gestão do plano, dentre as quais devem ser destacadas a valorização da avaliação da dimensão estratégica do plano e o fim das revisões anuais.

\section{Visão geral sobre a construção do PPA}

A dinâmica de construção do PPA é simples e lógica:

- Durante a campanha eleitoral, os candidatos devem apresentar um plano de governo, que espelha compromissos a serem assumidos caso sejam vitoriosos no pleito. 
- Decidida a eleição, o plano de governo do candidato vencedor deve servir como principal insumo para a elaboração de uma orientação estratégica de governo.

- Essa orientação estratégica deve subsidiar a elaboração das diretrizes estratégicas de cada setor, de forma que seja criado um grupo sinérgico e cooperativo entre as políticas governamentais.

- Estabelecidas as orientações estratégicas, devem ser definidas as políticas propriamente ditas, que serão materializadas por meio dos programas e ações (orçamentárias ou não) que os compõem.

- Paralelamente a essas definições, é realizada uma projeção do cenário fiscal para o período do plano, de forma a dimensionar a disponibilidade de recursos orçamentários para a implementação dos programas.

Essa lógica de construção costuma ser representada por uma pirâmide ${ }^{11}$, conforme figura abaixo.

A formulação de um programa está baseada na identificação de um problema ou em uma demanda da sociedade ou de segmentos dela, bem como de potencialidades a serem exploradas que, ao serem reconhecidas politicamente, passam a integrar a agenda de governo. A identificação desses problemas, demandas ou potencialidades deve ser estabelecida como um desdobramento das orientações estratégicas, de forma a garantir coerência interna ao plano.

Os problemas, demandas ou potencialidades $^{12}$ devem ser dimensionados, preferencialmente por indicadores já consagrados, de modo a estabelecer de forma segura qual a sua área de abrangência e quais as parcelas da sociedade envolvidas com o tema.

Em seguida, devem ser identificadas todas as causas responsáveis pelo problema caracterizado. Nesse momento, é importante uma avaliação acerca do número de causas relacionadas ao problema, bem como a sua abrangência. Isso porque a cada causa deve ser atribuída uma ação responsável por atacá-la. Nesse sentido, um número excessivo de ações pode inviabilizar uma gestão coordenada entre elas, o que prejudicaria os esforços direcionados ao enfrentamento do problema. Por outro lado, o conjunto de ações deve ser suficiente para a superação do problema, que pode, portanto, vir a ser redimensionado a partir da identificação de suas causas.

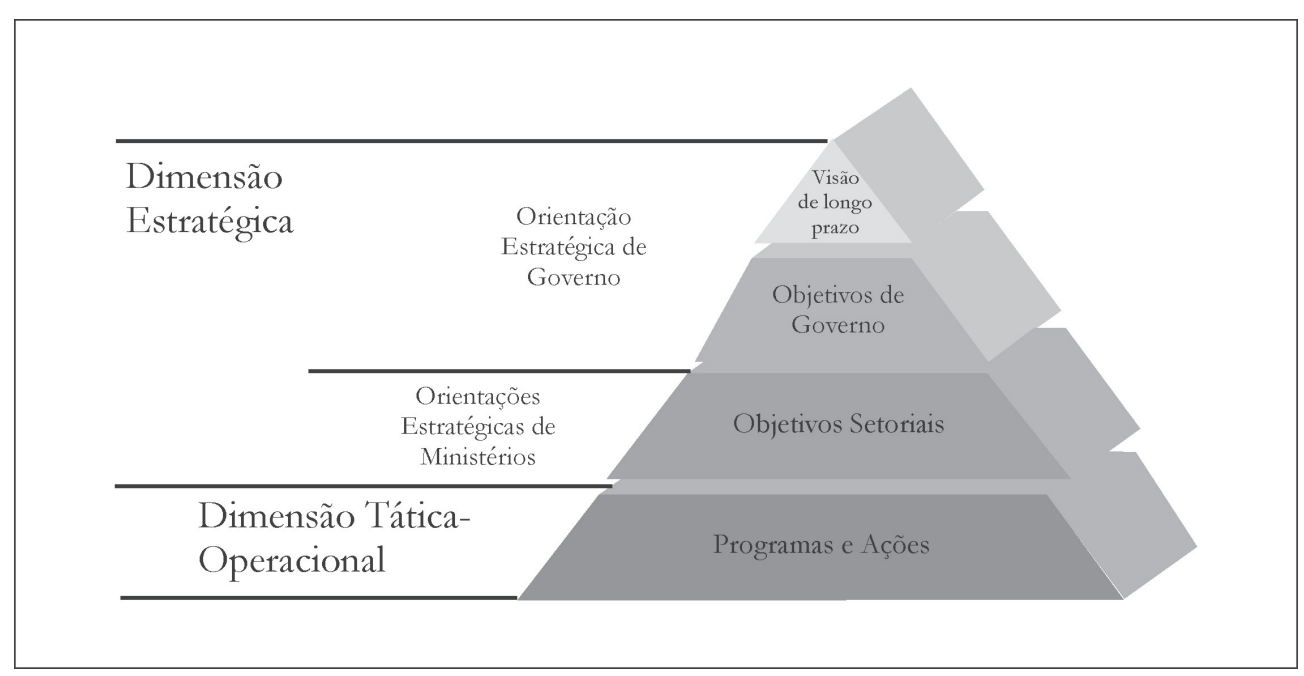


Por fim, a metodologia do PPA prevê que a cada ação deve corresponder um único produto, que é um bem ou serviço oferecido. Dimensionado o problema - e identificadas as suas causas e as respectivas ações necessárias e suficientes para o seu enfrentamento, capazes de alterar a realidade diagnosticada -, é concebido o programa.

A lógica de construção de um programa do PPA tem como importantes bases teóricas o Planejamento Estratégico Situacional (PES) ${ }^{13}$ e o Marco Lógico, e é representada no manual de elaboração pela figura abaixo ${ }^{14}$.

Considerando essa dinâmica, fíca evidente a necessidade de coordenação entre os diversos atores que vão construir o PPA, desde a sua visão estratégica até a definição das intervenções específicas, por meio dos programas e ações. Esse papel de coordenação - de responsabilidade do Ministério do Planejamento, Orçamento e Gestão (MP) - assume considerável complexidade, uma vez que a composição dos ministérios, em muitos casos, não respeita uma identidade programática, mas é formada em razão de acordos políticos. Independente do aspecto político, o trabalho de harmonizar o planejamento das diversas áreas setoriais também encontra obstáculos técnicos, já que entre os diversos setores, há relevantes diferenças entre as técnicas de planejamento praticadas.

\section{O modelo de integração entre planejamento, orçamento e gestão}

Até 1999, o conjunto das ações governamentais era organizado, tanto no PPA como nas leis orçamentárias, em função de atribuições institucionais. As ações, contudo, não possuíam uma relação entre si, apenas a organização sob a mesma unidade orçamentária e função de governo; era a denominada classificação funcional-programática. Apesar dos PPAs anteriores apresentarem diretrizes, objetivos e metas, não era estabelecida uma relação entre as ações governamentais, tampouco era abordado como essas intervenções contribuiriam para alterar a realidade e promover o desenvolvimento.

De acordo com relatório produzido pelo Banco Mundial em 2002, o PPA 2000-2003 aproveitou a experiência bem

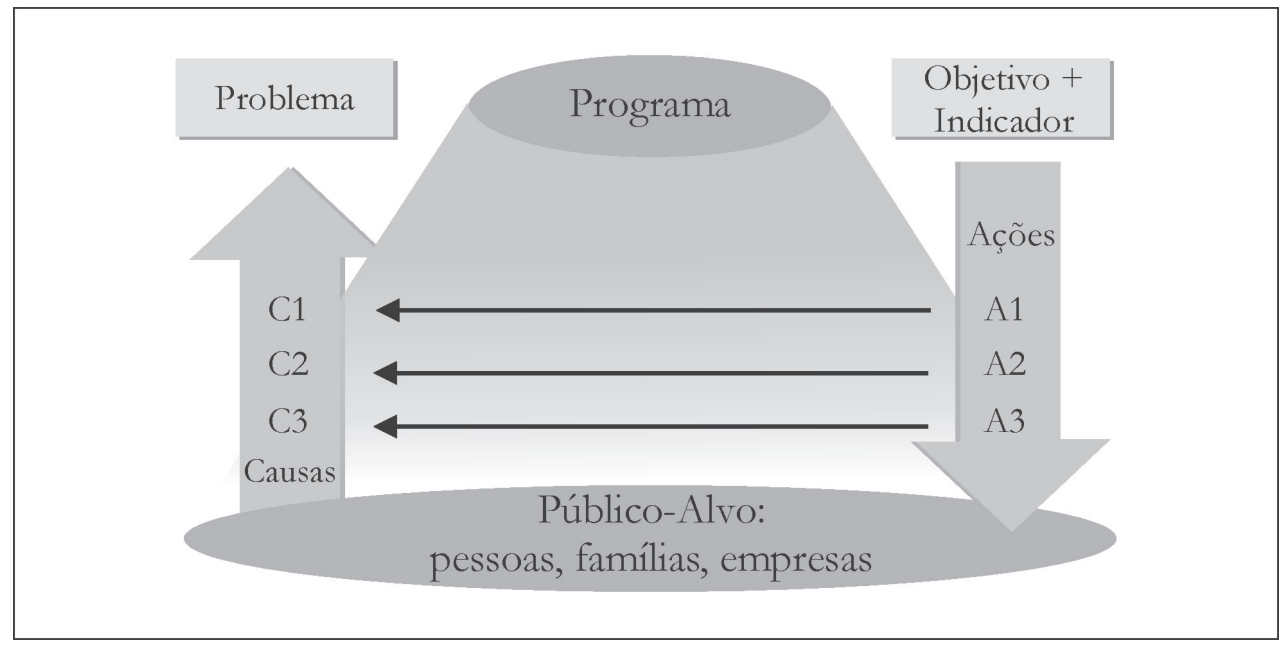


sucedida anterior e introduziu técnicas destinadas a transformar a administração pública burocrática tradicional numa estrutura organizacional voltada para as demandas da sociedade, utilizando-se de um gerenciamento com foco em resul$\operatorname{tados}^{15}$ (Banco Mundial, 2002).

O PPA 2000-2003 representou um marco para o planejamento em razão da criação do programa como unidade de gestão, que organizou a ação governamental em função de problemas e/ou demandas identificadas na sociedade, com foco em resultados. Ainda no ano 2000, a lei orçamentária adotou a mesma estrutura, e a avaliação das ações governamentais também passou a considerar os programas, sendo implementado o modelo de integração entre plano, orçamento e gestão.

O programa como unidade de gestão também foi importante por estabelecer uma linguagem comum aos instrumentos de planejamento e orçamento. Com isso, deu materialidade ao plano de governo, na medida em que expôs a pretensão de implantação das políticas frente à disponibilidade fiscal. No mesmo sentido, deu maior transparência ao orçamento, ao associar as despesas previstas a um objetivo definido de transformação na sociedade. $\mathrm{O}$ aspecto da gestão está materializado na incorporação de um processo sistemático de monitoramento, avaliação e revisão do plano (e consequentemente, das prioridades orçamentárias). O Banco Mundial exaltou o PPA como um avanço, ao contribuir para a elaboração de um planejamento em base fiscal realizável, e destacou o esforço do governo em avaliar o desempenho dos programas de forma transparente:

Todo o orçamento do governo federal foi dividido em 388 programas, cada um com objetivos claros, indicadores de execução física e financeira e um gestor. O governo também manteve a coerência entre o plano e a estrutura macroeconômica de médio prazo para evitar uma fragilidade típica dos planos governamentais - a falta de realismo fiscal. Também, pela primeira vez, o governo realizou uma avaliação sistemática e abrangente dos programas do PPA, com base em autoavaliações dos gestores dos programas. Em 2001 e 2002, os relatórios de avaliação foram apresentados ao Congresso e tornados públicos, o que é outra demonstração do compromisso do governo com a transparência e a melhoria de gestão. (BANCO Mundial, 2002). ${ }^{16}$

Diferente da funcional-programática, as ações passam a ser agrupadas em razão da contribuição para um objetivo comum. No mesmo sentido, a própria criação das ações incorpora uma dinâmica diferente, sendo justificada como intervenção necessária para superação de uma causa determinada de certo problema, e não apenas como cumprimento de uma atribuição institucional.

Essa mudança representou um avanço, pois ao colocar em prática uma gestão voltada para resultados, estabeleceu o compromisso do Estado em alterar a realidade, e não apenas em prestar serviços. Nesse sentido, a criação do programa também permitiu a identificação de sobreposição de esforços, bem como a de eventuais parcerias, seja entre instituições públicas, seja com entidades privadas.

A designação de um gerente responsável por cada programa, atribuindo responsabilização pelos resultados esperados, representou uma quebra de paradigma na estrutura burocrática do serviço público. Ronaldo Coutinho, ao 
mencionar os estudos de preparação para o PPA 2000-2003, expressa que as inovações conceituais e metodológicas representaram, certamente, um avanço:

Pensar por problemas e enfrentá-los mediante ações organizadas por programas com objetivos definidos, com a articulação do plano ao orçamento, permite chegar muito mais perto da complexidade do mundo real do que na forma tradicional de fazer planejamento e orçamento (área temática, setores da administração e subprogramas referenciados apenas por metas a alcançar). Conceber ações (projetos, atividades e ações normativas) definindo com rigor seus produtos (um por ação), suas metas, seus custos e prazos é criar possibilidades para a prática de uma administração mais gerencial no setor público. (GARCIA, 2000, p. 23).

\section{O fim do PPA: uma crítica ao modelo adotado}

Ao examinar a implementação de um grupo seleto de programas nos dois primeiros anos do PPA 2000-2003, o Banco Mundial reconheceu avanços, tais como: valorização de desempenho; maior disponibilidade de informações e melhor definição dos gastos orçamentários; maior preocupação com resultados oferecidos à sociedade. Ressaltou, contudo, que o PPA não era o único fator impulsionador dessas mudanças:

Uma análise de quatro programas selecionados no Plano Plurianual nos setores de saúde e de transportes sugere que o PPA se mostra um catalisador para promoção de uma cultura de foco no desempenho: orçamento e informações sobre a execução orçamentária são cada vez mais úteis para as pessoas dentro e fora do governo; a margem de discricionaridade política tem sido reduzida por uma melhor definição dos itens de despesa; e os funcionários públicos estão cada vez mais habituados a pensar sobre as necessidades finais a que devem servir. Mas esses efeitos observados são modestos (e impossíveis de medir). Eles são mais fortes em alguns programas do que em outros, e o PPA é, sem dúvida, apenas um item de um amplo conjunto de fatores (incluindo as demandas da sociedade) que impulsionam as mudanças. ${ }^{17}$

Estudo mais recente, realizado por técnicos do Banco Mundial em 2006, ao avaliar a contribuição do PPA para o desempenho da gestão pública, ressalta que o maior mérito consiste na organização das ações de governo de forma mais transparente:

Os programas talvez tenham sido mais úteis para fins de controle externo do que para a gestão interna dos ministérios. A CGU e o TCU utilizam bastante os programas como critérios para a definição de suas ações de auditoria. (...) O uso do PPA por parte dos órgãos de fiscalização demonstra cabalmente a contribuição do PPA à transparência do governo. (Matsuda e Outros, 2006, p. 14 e 15).

O mérito da transparência, contudo, não pode ser associado exclusivamente ao PPA mas, principalmente, à organização das ações governamentais por meio de programas, estrutura também adotada pela lei orçamentária. Nesse aspecto, o "mérito" do PPA seria, então, apresentar 
uma projeção das despesas orçamentárias para três anos além do exercício orçamentário subsequente, muito embora essa projeção não seja considerada nem mesmo como referência quando da elaboração da LOA.

Dessa feita, decorridos dez anos da implantação do modelo atual, é possível afirmar que o PPA constitui instrumento de trabalho principalmente para os órgãos de controle, mas, para os planejadores e tomadores de decisão, limita-se a peça burocrática. Essa constatação, como vimos, consiste em afronta ao previsto pela Constituição Federal de 1988, que conferiu ao Plano Plurianual o papel de instrumento de planejamento e gestão estratégica, orientador dos planejamentos regionais e setoriais e das leis orçamentárias.

É possível afirmar que esse descrédito do PPA como instrumento de planejamento e gestão estratégica ganhou contornos mais evidentes a partir de 2007, quando a Presidência da República ignorou os trabalhos de preparação do PPA 2008-2011 desenvolvidos no âmbito do Ministério do Planejamento e lançou uma série de planos em paralelo, com destaque para o Programa de Aceleração do Crescimento (PAC), o Programa de Desenvolvimento da Educação (PDE) e a Agenda Social (AS).

Com isso, o governo federal elegeu novas formas para definir e comunicar quais eram as suas prioridades e metas. É verdade que todas essas iniciativas tiveram que ser incluídas no PPA para serem levadas a efeito, conforme previsão constitucional, mas essa etapa foi cumprida como um procedimento burocrático.

A esse passo, resta-nos identificar as razões para o descrédito do PPA como instrumento de planejamento e gestão estratégica, inclusive junto à Presidência da República.
Em primeiro lugar, deve ser apontada a estratégia de submeter toda a administração a um mesmo modelo de planejamento e gestão, ignorando o objeto de cada política pública, além das peculiaridades organizacionais. O programa, como unidade de gestão, foi estabelecido de maneira uniforme, o que importa dizer que a metodologia de programação para a área de infraestrutura é a mesma para a área social, e mais, não há distinção entre programas finalísticos e de apoio ao Estado. Essa crítica foi apontada em relatório produzido por técnicos do Banco Mundial em 2006:

Com o passar do tempo, o modelo do PPA mostrou duas falhas fundamentais: a insistência em preservar o formato "puro" dos programas e a preferência pela universalidade em lugar da seletividade. O ambicioso enfoque "puro" visava a submeter todas as ações de governo a uma formatação padronizada e impor a lógica dos programas como diretriz central de organização do governo. Essas ideias são intuitivamente lógicas e o formato dos programas, inquestionavelmente, favorece a transparência e dá ênfase aos produtos e resultados. Em comparação com a experiência internacional, trata-se realmente de um projeto muito ambicioso. Entretanto, os programas não podem ser identificados sem ambiguidades e a lógica dos programas pode ser incompatível com a das organizações reais e com as pressões orçamentárias. Mais ainda, a lógica dos programas pode ser boa para as ações desenvolvimentistas, mas não fazer sentido nas ações rotineiras. 
A universalidade ignora as diferenças entre as organizações quanto aos objetivos e à competência técnica; ela presume que a melhoria do desempenho é o produto da aplicação de uma fórmula padrão (do tipo "tamanho único"), sem levar em conta diferenças de objetivos e competências; ela pulveriza a distribuição dos recursos; ela não sinaliza claramente as reais prioridades do governo (e por isso não conta com o apoio da própria Presidência); ela gera uma burocracia que não produz resultados. Portanto, está comprovado que o uso de um enfoque padronizado para promover a melhoria da gestão de tipos diferenciados de atividades é ineficaz. (Matsuda e Outros, 2006, p.32).

Em segundo lugar, apontamos o detalhamento excessivo do PPA, obedecendo à estrutura orçamentária. Isso porque o PPA não se restringe a apontar diretrizes, objetivos e metas organizadas por meio de programas, mas discrimina inclusive as ações orçamentárias e nãoorçamentárias, com previsão de recursos. Essa estrutura desvia a discussão estratégica de planejamento, essencialmente política, para um enfoque técnicoorçamentário. $\mathrm{Na}$ prática, o PPA foi incorporado à dinâmica orçamentária, tornando-se pouco capaz de orientá-la.

Por mais, é preciso reconhecer que a construção da lei orçamentária segue uma estratégia que, por vezes, é muito distinta da esperada em um exercício de planejamento. Exemplo característico é a tendência, no orçamento, de se criar provisões mais gerais (as chamadas "ações guarda-chuva”), uma vez que isso pode beneficiar a gestão por facilitar a realização do gasto. No planejamento, contudo, espera-se que os produtos a serem oferecidos à sociedade sejam bem delimitados. Um exemplo representativo de como o rigor metodológico prejudica o plano (e o orçamento) está associado à regra de que cada ação possui apenas um único produto, o que incentiva a criação de produtos do tipo "população beneficiada", "município atendido", que pouco contribuem para avaliar a efetividade do plano, ou mesmo a qualidade do gasto orçamentário.

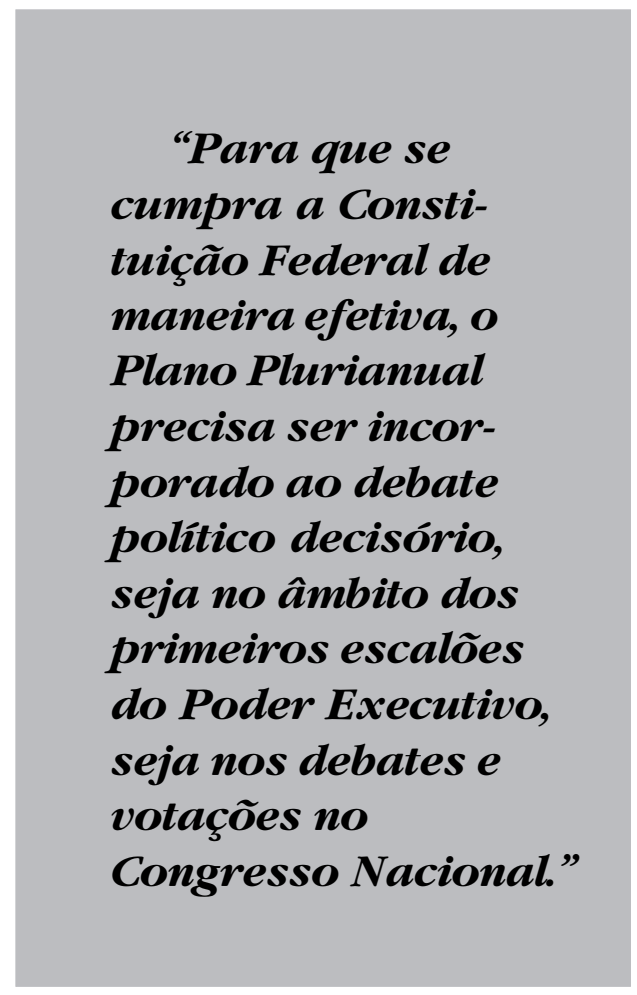

Em terceiro lugar, a dubiedade teleológica do PPA, qual seja, a pretensão de construção de um instrumento que, ao mesmo tempo, seja reconhecido como de planejamento e gestão estratégica, assim como de transparência dos gastos públicos. A expectativa de que um mesmo instrumento cumpra dois papéis distintos nos parece uma falha conceitual e 
estratégica que, com o tempo, acaba por desacreditá-lo para os dois fins previstos. Essa dicotomia já foi abordada em literatura internacional e faz parte de relatório de técnicos do Banco Mundial sobre o PPA ${ }^{18}$.

Já se disse que um mesmo instrumento não pode atender a dois objetivos diferentes. Um dos instrumentos é o PPA, que enfrenta dificuldades em servir aos múltiplos objetivos de planejamento e formulação de políticas (no sentido de identificação de problemas e respectivos programas e de racionalização dos recursos para atendê-los) e de gestão financeira e organizacional. Por exemplo, o Departamento de Defesa dos EUA usa o orçamento-programa para fins de planejamento, mas as suas verbas são alocadas às unidades organizacionais (...). Se os programas do PPA não fossem usados para fins orçamentários, a situação brasileira seria parecida com a do modelo de racionalização de políticas dos EUA. Entretanto, como os programas do PPA são os critérios de alocação de verbas orçamentárias, está feito o jogo de manipulação bilateral de programas para controlar verbas. Kim e outros (2006) consideram axiomático manter em separado as duas diferentes funções do orçamento (planejamento e gasto), pois "é extremamente difícil conseguir (que a) estrutura organizacional se subordine ao planejamento, mesmo nos países que praticam o orçamento-programa, pois são os órgãos de governo que gastam o dinheiro e se responsabilizam pelos resultados. (MATsuda e Outros, 2006, p.27).
Em quarto lugar, a estratégia de gestão do Plano adotada pelo Ministério do Planejamento, que privilegia o monitoramento da execução orçamentária das ações em detrimento de uma avaliação do programa como um todo. Outra deficiência diz respeito à sua atuação sobre as restrições ao desempenho dos programas, apontadas pelos gerentes, a qual é praticamente inexistente, mesmo quando essas restrições estão registradas em sistema mantido pelo próprio MP, o Sistema de Informações Gerenciais e de Planejamento (SIGPlan).

Ainda, a abordagem essencialmente setorial estabelece certo enfrentamento entre o órgão central e os ministérios responsáveis pela implementação das políticas, e pouco contribui para a superação de problemas ou apresentação de oportunidades.

Todos esses fatores impõem forte resistência ao PPA no âmbito da administração - inclusive por parte da Presidência da República, como vimos - de forma que seu trâmite está incorporado apenas aos procedimentos burocráticos, mas ignorado no âmbito político-decisório. Como reflexo imediato, promove-se o desinteresse também no âmbito legislativo, e o trâmite do PPA no Congresso Nacional não tem inspirado maiores debates.

\section{Planejamento como expressão de um compromisso político: o resgate do PPA}

Para que se cumpra a Constituição Federal de maneira efetiva, o Plano Plurianual precisa ser incorporado ao debate político decisório, seja no âmbito dos primeiros escalões do Poder Executivo, seja nos debates e votações no 
Congresso Nacional, de forma a ser reconhecido como efetivo instrumento de planejamento e gestão estratégica.

Esse envolvimento dos tomadores de decisão é requisito indispensável para o sucesso do PPA pois, conforme lição de Matus, extraída do Planejamento Estratégico Situacional (PES), "planeja quem decide"19. Assim, o PPA deve valorizar o debate político-estratégico, em contraposição ao debate técnico-orçamentário.

Para tanto, deve ser promovida uma flexibilização da metodologia de elaboração do PPA, de forma que cada setor possa apresentar suas metas e prioridades de acordo com a sua experiência de planejamento, devendo ser explicitada qual a base teórica e técnica utilizada. Com isso, além de valorizar a experiência de planejamento de cada setor, cria-se um intercâmbio de experiências que pode, inclusive, fortalecer a metodologia oferecida pelo MP por meio de um aprimoramento constante.

O PPA deve promover uma valorização dos aspectos estratégicos da programação, em especial a definição do objeto da política pública, os indicadores que o caracterizam e as metas perseguidas para a modificação da realidade. Considerando a estrutura atual, deve ser privilegiado o debate acerca dos atributos do programa, tais como objetivos, indicadores e metas, em detrimento da discriminação das ações orçamentárias.

Outro importante fator é valorizar a regionalização do PPA, conforme preconiza a Constituição Federal. De fato, as diferenças existentes no país são aspecto relevante para o planejamento governamental, e deveriam refletir em maior diversidade e especificidade as políticas públicas. Essa regionalização, contudo, não deve ser entendida como a simples localização do gasto, mas como a efetiva construção do planejamento estratégico em base territorial. Isso implica dizer que os problemas ou demandas devem ser caracterizados regionalmente, resultando em estratégias de atuação específicas.

Em resumo, a abordagem territorial representa um aprimoramento do planejamento, tanto no campo técnico quanto em relação à capacidade de mobilização política. Avanço técnico porque o Ministério do Planejamento poderia produzir estudos e diagnósticos territoriais, em complemento aos estudos setoriais já realizados pelos ministérios. Avanço na capacidade de mobilização política pelo estabelecimento de um canal permanente de discussão de planejamento governamental junto aos entes subnacionais e Congresso Nacional.

Estabelecida essa dinâmica de planejamento, torna-se possível a elaboração de um PPA que efetivamente incorpore a perspectiva territorial na definição das políticas públicas e das metas governamentais.

Por fim, deve ser esclarecido que não cabe ao PPA promover a transparência do gasto público, mas sim orientá-lo. A preocupação com a transparência pode estar a cargo da lei orçamentária que, oportunamente, pode apresentar uma previsão plurianual, mas, principalmente, deve ser fortalecida na execução dos gastos, em especial por meio do aprimoramento dos registros no Sistema Integrado de Administração Financeira do Governo Federal (Siafi). Essa definição conceitual é indispensável para o reconhecimento do PPA como instrumento estratégico e, consequentemente, seu constante aprimoramento para esse fim. 


\section{Conclusão}

Ao submeter o PPA a uma rígida estrutura orçamentária, o modelo adotado subverteu o comando constitucional: ao invés de orientar as alocações orçamentárias, o Plano Plurianual é definido por elas. Nesse contexto, até mesmo a Presidência da República lhe atribui pouca relevância, considerando-o peça meramente burocrática, o que explica o surgimento de novos instrumentos de planejamento, como o Programa de Aceleração do Crescimento (PAC).
Para tornar efetivo o seu papel de instrumento de planejamento e gestão estratégica, o PPA deve ser capaz de abrigar o debate político acerca da definição das metas. Para tanto, deve comportar maior flexibilidade metodológica e desvincularse parcialmente da estrutura orçamentária, sendo capaz de mobilizar os tomadores de decisão e representar com clareza o compromisso político assumido.

(Artigo recebido em dezembro de 2009. Versão final em junho de 2010)

\section{Notas}

1 Entende-se como estratégico aquele documento que estabelece definições no campo políticodecisório, em contraposição às decisões tático-operacionais.

2 Fonte: Manual de Elaboração do PPA 2008-2011.

3 Matos, Patrícia de Oliveira. Análise dos Planos de Desenvolvimento Elaborados no Brasil após o II PND. Dissertação de Mestrado em Economia Aplicada. Orientação: Prof. Dr. Pedro Carvalho de Mello. Escola Superior de Agricultura Luiz de Queiroz, Universidade de São Paulo. Piracicaba/SP, outubro de 2002, p.25.

4 PPA 1991-1995 - Lei ñ $0.173 / 91$ e alterações posteriores.

5 “O primeiro PPA foi desenhado como um Orçamento Plurianual de Investimento (OPI) ampliado (em tempo e em tipos de despesa), sem estar suportado por um projeto de governo preciso para o qual fizesse a mediação com os orçamentos anuais. Sua elaboração deu-se sob enorme improvisação, pois os responsáveis por sua redação trabalhavam sem contato regular com os dirigentes máximos, que, por sua vez, apenas declaravam intenções vagas, anunciavam programas com nomes pomposos e sem substância. Muitas palavras de ordem, sem indicação de como realizá-las na prática." (GARCIA, 2000, p.13).

6 Esse mapeamento foi produzido a partir do Estudo dos Eixos de Integração e Desenvolvimento.

7 PPA 2000-2003 - Lei $n^{\circ}$ 9.989/00 e alterações posteriores.

8 PPA 2004-2007 - Lei no 10.933/04 e alterações posteriores.

9 Matsuda, Yasuhiko; Shepherd, Geoffrey e Wenceslau, Juliana. Gestão e Avaliação no Contexto do Plano Plurianual (PPA): Institucionalização sem Impacto?. Relatório produzido por funcionários do Banco Mundial a pedido do Ministério do Planejamento, Orçamento e Gestão, não consistindo estudo oficial do BIRD. Brasília, nov. 2006, p. 7 e 8: "De modo geral, este PPA manteve-se fiel ao modelo dos anteriores, mas apresenta algumas mudanças. (...) A elaboração do PPA 2004-2007 não foi antecedida por novos exercícios metodológicos semelhantes ao estudo dos Eixos. Resulta daí 
que este PPA parece ter perdido um pouco da indicatividade que caracterizava o seu predecessor. Em vez disso, a nova equipe trazida pelo Presidente Lula formulou o PPA com base num amplo processo de consultas populares levado a cabo nos níveis nacional e estadual, provavelmente com a intenção de promover um ajuste maior entre os programas federais e as prioridades dos Estados. Infelizmente, a falta de acompanhamento sistemático dos resultados desse processo de consultas contribuiu para o descrédito dessa iniciativa de planejamento participativo".

10 PPA 2008-2011 - Lei no 11.653/2008.

11 Fonte: Manual de Elaboração do PPA 2008-2011.

12 A partir desse momento, quando for mencionado problema, deve ser entendido como o conjunto de problemas, demandas ou potencialidades.

13 Matus, Carlos. Política, Planejamento e Governo. Brasília: IPEA, 1993.

14 Fonte: Manual de Elaboração do PPA 2008-2011.

15 "Brazil's PPA is a unique and serious attempt to use techniques of planning to transform the Brazilian Federal bureaucracy into a modem, results-oriented entity that effectively provides public goods and services that are demanded by citizens. Its goals of revamping the state's capacity to plan and instilling a culture of entrepreneurial management in the public sector are ambitious, yet its approach to implementation is advisedly cautious. Its conceptual design is built explicitly on experiences of the previous PPA, with which a series of management innovations were successfully piloted. The development of the Plan followed a careful preparation process that lasted more than two years. The 'model' is multi-faceted and highly complex, as is the Brazilian Federal bureaucracy. It is also an evolving process, in which the Government is constantly introducing adjustments to the model's design as it encounters practical implementation challenges."

16 Tradução livre do original em inglês: "The entire federal government budget was broken down into 388 Programs, each with clear objectives, indicators for financial and physical execution, and a Manager. The government also maintained consistency between the Plan and the mediumterm macroeconomic framework to avoid a typical weakness of government plans - lack of fiscal realism. Also, for the first time, the government carried out a systematic and comprehensive evaluation of the PPA Programs, based on Program Managers' selfassessments. In 2001 and 2002, the evaluation reports were presented to Congress and made public, which is another demonstration of the government's commitment to transparency and managerial improvement".

17 Tradução livre do original em inglês: "An examination of four selected PPA Programs in the health and the transport sectors suggest that the PPA is proving a catalyst in advancing a culture of performance orientation: budget and budget execution information is becoming more useful to people inside and outside government; the area for political discretion is being reduced by better definition of spending items; and public servants are getting more into the habit of thinking about the final needs they are supposed to serve. But these observed effects are modest (and impossible to measure); they are stronger in some Programs than others; and the PPA is no doubt only one of a broader set of factors (including public demand) impelling the changes".

${ }^{18}$ Matsuda e outros (2006), p.35.

${ }^{19}$ Matus (1985) apud Azevedo, Creuza da S. Planejamento e Gerência no Enfoque EstratégicoSituacional de Carlos Matus. Caderno de Saúde Pública, Rio de Janeiro, v.8, n.2, 1992, p.130. 


\section{Referências bibliográficas}

Azevedo, Creuza da S. Planejamento e Gerência no Enfoque Estratégico-Situacional de Carlos Matus. Caderno de Saúde Pública, Rio de Janeiro, v.8, n.2, 1992.

Banco Mundial. Brazil Planning for Performance in the Federal Government. Review of the Pluriannual Planning. Relatório n⿳丷ㅡㄹ 22870-BR. Washington, dez. 2002.

Brasil. Constituição (1988) Constituição da República Federativa do Brasil.

BRASIL. Lei no 8.173, de 30 de janeiro de 1991 e alterações posteriores (PPA 1991-1995). . Lei n⿳⺈ 9.276, de 09 de maio de 1996 e alterações posteriores (PPA 19961999).

2003). . Lei no 9.989, de 21 de julho de 2000 e alterações posteriores (PPA 20002004-2007). . Lei n⿳ 10.933, de 11 de agosto de 2004 e alterações posteriores (PPA 2011).

Brasil. Ministério do Planejamento, Orçamento e Gestão. Secretaria de Planejamento e Investimentos Estratégicos. Manual de Elaboração: PPA 2008-2011. Brasília: MP, 2007.

. Ministério do Planejamento, Orçamento e Gestão. Secretaria de Planejamento e Investimentos Estratégicos. Estudo para Subsidiar a Abordagem da Dimensão Territorial do Desenvolvimento Nacional no Plano Plurianual 2008-2011 e no Planejamento Governamental de Longo Prazo. Documento de Referência, outubro de 2006. Disponível em: http://sig.mct.gov.br/docs/Doc\%20Ref $\% 20$ Planejamento $\%$ 20Territorial.pdf. Acesso em: 30 nov. 2009.

BRASIL. Tribunal de Contas da União. Secretaria de Fiscalização e Avaliação de Programas de Governo. Relatório de Monitoramento: Programa Saúde da Família. Brasília, 2006.

Garcia, Ronaldo Coutinho. A Reorganização do Processo de Planejamento do Governo Federal: o PPA 2000-2003. Texto para Discussão nº. 726. Brasília: IPEA, 2000.

Matos, Patrícia de Oliveira. Análise dos Planos de Desenvolvimento Elaborados no Brasil após o II PND. 2002. Dissertação (Mestrado em Economia Aplicada) - Universidade de São Paulo, Piracicaba/SP.

Matsuda, Yasuhiko; Shepherd, Geoffrey e WenCeslau, Juliana. Gestão e Avaliação no Contexto do Plano Plurianual (PPA): Institucionalização sem Impacto? - Relatório produzido por técnicos do Banco Mundial a pedido do Ministério do Planejamento, Orçamento e Gestão. Brasília, nov. 2006.

Matus, Carlos. Politica, Planejamento e Governo. Brasília: IPEA, 1993.

Pares, Ariel e Valle, Beatrice. A Retomada do Planejamento Governamental no Brasil e seus Desafios. In: Giacomoni, James e Pagnussat, José Luiz (Orgs). Planejamento e Orçamento Governamental. Coletânea, v.1. Brasília: ENAP, 2006. 


\section{Resumo-Resumen-Abstract}

\section{O PPA como instrumento de planejamento e gestão estratégica}

Luiz Fernando Arantes Paulo

Criado pela Constituição Federal de 1988, o Plano Plurianual (PPA) ainda padece de uma crise de identidade. Não obstante a previsão de orientador das peças orçamentárias, o certo é que ainda não foi reconhecido como um efetivo instrumento de planejamento e gestão estratégica. Na administração federal, ainda há uma considerável resistência à sua efetiva incorporação. Como reflexo, a sua tramitação no Congresso Nacional também não mobiliza os parlamentares, que se limitam à discussão de itens reproduzidos no orçamento anual. Nesse contexto, o PPA é comumente definido como um documento burocrático e de pouca utilidade. No presente trabalho, procuramos demonstrar que o legislador constituinte criou o PPA para ser um instrumento de planejamento e gestão estratégica, com o papel de integrar o planejamento à execução das políticas públicas. Contudo, a estrutura e as opções metodológicas adotadas ao longo dos anos o têm afastado desse propósito.

Palavras-chave: planejamento governamental, Plano Plurianual, gestão pública

\section{El Plan Plurianual como un instrumento estratégico de planificación y administración} Luiz Fernando Arantes Paulo

Creado por la Constitución Federal de 1988, el Plan Plurianual (PPA) sufre de una crisis de identidad. En la administración federal, existe una considerable resistencia a reconocerlo como un instrumento estratégico de planificación y administración, y que es comúnmente definido como un texto burocrático de poca utilidad. En el trabajo, hemos intentado demostrar cómo la estructura y las opciones metodológicas aprobadas a lo largo de los años han alejado el PPA de su propósito.

Palabras clave: administración pública, planificación plurianual, planificación del gobierno

\section{Pluriannual Plan as an instrument of planning and strategic management}

Luiz Fernando Arantes Paulo

Created by the Federal Constitution of 1988, the Pluriannual Plan (PPA) still suffers from an identity crisis. In the federal administration, there is a considerable resistance in recognizing it as an instrument of planning and strategic management, and it's commonly defined as a bureaucratic document of little usefulness. In the present work, we tried to demonstrate how the structure and the methodological options adopted along the years have been moving PPA away from its purpose.

Keywords: public administration, Pluriannual Plan, government planning

Luiz Fernando Arantes Paulo

É advogado, bacharel em Direito pela Unesp e especialista em Gestão Pública pela ENAP. Atua como analista de Planejamento e Orçamento desde 2004. Contato: luiz.paulo@planejamento.gov.br. 


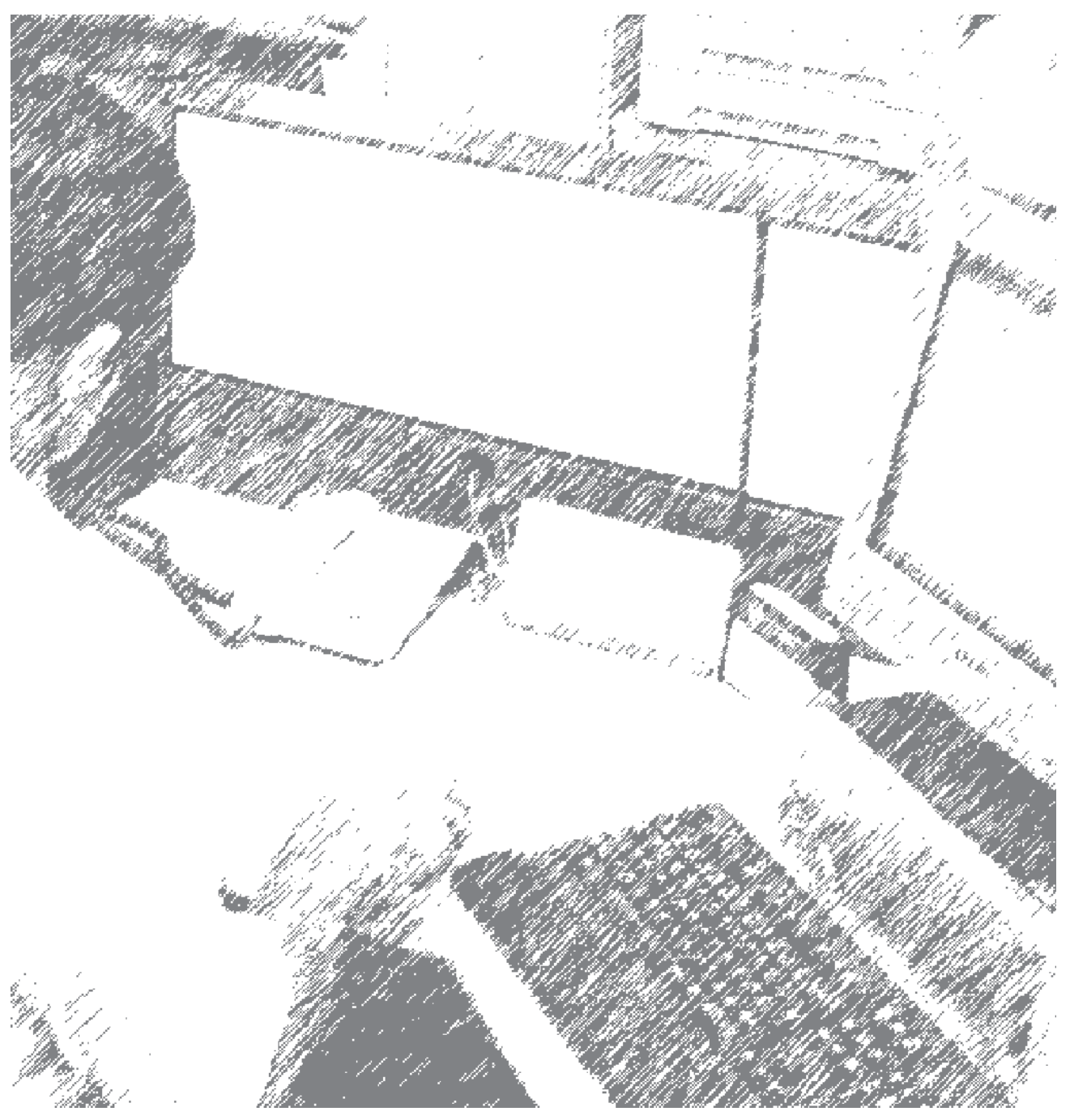

